\title{
Cross-wire projection welding of aluminium alloys-pneumatic and electromechanical electrode force systems
}

\author{
Zygmunt Mikno ${ }^{1}$
}

Received: 17 September 2018 / Accepted: 11 February 2019 / Published online: 7 March 2019

(C) The Author(s) 2019

\begin{abstract}
The article discusses the optimisation of the conventional resistance welding process performed using the pneumatic (electrode) force system (PFS) by applying the electromechanical force system (EFS) and a new algorithm enabling the control of the force and/or displacement of welding machine electrodes, particularly during the flow of current. The research work described in the article aimed at the in-depth numerical analysis of the projection cross-wire welding of bars made of aluminium alloy Al 5182, having a diameter of $4 \mathrm{~mm}$, in relation to two electrode force systems, i.e. the PFS and the EFS. The research-related tests involved experimental verification. In addition, the article presents advantages of the new control system. Calculations were performed until one of the adopted boundary conditions, i.e. the maximum welding time, the maximum penetration of wires (bars), the occurrence of expulsion or the exceeding of the temperature limit in the contact between the electrode and the welded material was obtained. For the PFS, it was observed that the ring weld was formed within the entire range of welding parameters. Numerical calculations were performed using SORPAS software. Technological welding tests were performed using inverter welding machines $(1 \mathrm{kHz})$ provided with various electrode force systems. The research also involved the performance of metallographic and strength (peeling) tests as well as measurements of welding process characteristic parameters (welding current and voltage). The welding process optimisation involving the use of the EFS and the application of the hybrid algorithm of force control resulted in (i) more favourable space distribution of welding power, (ii) energy concentration in the central zone of the weld, (iii) favourable (desired) melting of the material within the entire weld transcrystallisation zone, (iv) obtainment of a full weld nugget and (v) over $20 \%$ longer weld nugget diameter.
\end{abstract}

Keywords Resistance welding · Electromechanical force system · Cross-wire welding · Projection welding · Electrode force · FEM

\section{Introduction}

Force is one of the key parameters in the resistance welding process. The other parameters are the value of current and its flow time. During cross-wire projection welding (particularly of aluminium alloys) in a conventional application, i.e. using the pneumatic force system (PFS), it is very difficult, nearly impossible, to make a weld with a full weld nugget. Aluminium, when subjected to welding, gets plasticised very

Electronic supplementary material The online version of this article (https://doi.org/10.1007/s00170-019-03443-5) contains supplementary material, which is available to authorized users.

Zygmunt Mikno

zygmunt.mikno@is.gliwice.pl

1 Welding Institute, Gliwice, Poland quickly, which is responsible for the formation of the excessively large area of contact between elements being welded and, consequently, results in a rapid decrease in current density. These are not favourable conditions for the melting of materials to be/being welded. In addition, the PFS is characterised by high inertia and the impossibility of performing fast changes in force during the flow of current. For this reason, the value of pre-set force is usually constant and unfavourably too high. If the force is excessively high, the high deformation of welded elements (bars) may occur as a result. The overly low force may result in the formation of projection joint imperfections (expulsion caused by high temperature in contacts) [1]. In the PFS, force applied during welding results from specific force pre-set by a pneumatic cylinder. The displacement of electrodes results from the action of this force and of the changeable mechanical resistance of materials being welded. A significant disadvantage of the 
above-presented manner of control is the fact that neither force nor displacement (during the flow of current) is controlled.

An alternative solution requires another method enabling the performance of faster changes in force during the welding of materials [1-3]. In publication [1], Zhang et al. emphasise the growing popularity of the servomechanical (electromechanical) force system (EFS) and an advantage involving an increase in an electrode displacement rate during welding. Zhang et al. [2] inform about the possible extension of the window of technological parameters, improving the weldability of materials. In work [4], Tang et al. refer to the possible modulation of force and its fast changes, particularly at the end of the process of welding. Gould [5] emphasised an increase in electrode service life in spot resistance welding and the use of servomotors in the riveting technology. Zhang [6] and Slavick [3] stated that the EFS eliminated the dynamic impact of electrodes against a material subjected to welding (during initial force), which was characteristic of pneumatic actuators. The EFS enabled a gentle "touch" of an electrode against a material being welded. Slavick [3] enumerates other advantages of the EFS including (i) superior (faster) operation of a welding gun (servo) in space, (ii) greater repeatability of force, (iii) reduced noise, (iv) shorter welding time and (v) shorter movement during the closing and opening of the electrodes, extending the service life of mechanisms.

The tests presented in the article aimed to replace the PFS with the EFS. It was also important to appropriately control the servomotor in order to provide the controlled movement/ shift of electrodes, particularly during the flow of current. The control process has changed significantly, i.e. the displacement of electrodes is a pre-set parameter and resultant force depends on the displacement of electrodes and the resistance of the deformation of a contact area being heated. Available reference publications do not contain information concerning such a method of electrode movement control as the method presented in this study.

Mikno et al. [7, 8] describe a new control system and the results of its operation, particularly visible in projection welding. Mikno et al. [7, 9] present a new control system used during the welding of sheets with an embossed projection. Another application of the new solution, i.e. cross-wire welding and the welding of nuts, is presented by Mikno et al. in publications $[9,10]$ respectively.

In publications [7-9, 11] Mikno et al. present an entirely different solution, i.e. the slowing down of the displacement of an electrode during the projection welding of sheets with an embossed projection. This approach is new and characterised by advantages which are worth mentioning. The above-named idea can be used in another projection welding technology, i.e. in cross-wire welding. It is possible to reduce the penetration of bars and to generate more energy in the most desirable place, i.e. in the contact area between bars. The new idea of electrode displacement control significantly changes the previous approach to the course of the resistance welding process (projection cross-wire welding) and significantly affects the development of the entire research area (pressure welding).

The article constitutes a fragment of greater research, where the process of welding is analysed in respect of the application of variable electrode force or electrode displacement control. The new method of control is performed using the EFS. Research-related tests described in the article involved the use of the SORPAS 3D computational model.
Table 1 Simulation parameters

Time step increment
Pneumatic force system (PFS)
Electromechanical force system (EFS)
Time step
Electrical model
Thermal model
Mechanical model
Dynamic contact between objects
Air temperature
Heat transfer rate
Length $\times$ width
Electrode height
Welding current

Squeeze
100
100
0.1
Converge
Converg
$1.00 \mathrm{E}-5$
$1.00 \mathrm{E}-5$
$1.00 \mathrm{E}-5$

\section{Sliding}

Heat loss to the environment

20

300

Electrode dimensions

$10.0 \times 8.0 \quad \mathrm{~mm}$

$5 \mathrm{~mm}$ 
Fig. 1 Temperature distribution in the welding area (3D model). a Complete model. b Magnification from Fig. 4(c2)
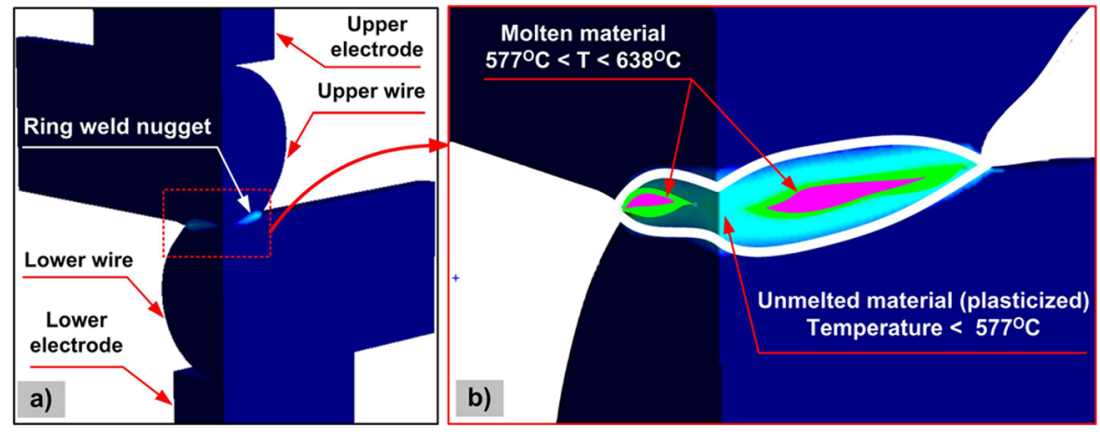

\section{FEM calculations}

The research-related FEM calculations were conducted using the SORPAS 3D version 4.0 software model [12]. The software programme enables the performance of related analyses, including coupled electro-thermo-mechanicalmetallurgical analyses. The equations of the FEM mathematical model, i.e. electric, thermal, metallurgical and mechanical, were discussed by Zhang in publication [13]. The above-named software features a module including the effect of a new force and a precise electrode movement solution, i.e. based on the EFS.

Simulation parameters for SORPAS (FEM computational software) used in the study and involving the use of the computational model are presented in Table 1.

A cross-wire projection welded joint made using the PFS is characterised by a thin layer of a molten material (metal subjected to welding). Usually, a weld is formed in the solid state at a temperature below the melting point. The foregoing results from the specific nature of the process, i.e. the melting of the material and the pushing of the plasticised material outside the weld (joint) by constant and unfavourable excessive force. The weld adopts the shape as presented in Fig. 1a; such a weld is referred to as a ring weld. As can be seen, the material in the central part of the weld is not melted (Fig. 1b).

The research-related calculations and experimental tests involved the use of aluminium bars grade $\mathrm{Al} 5182$, having a solidus temperature of $577^{\circ} \mathrm{C}$ and a liquidus temperature of $638^{\circ} \mathrm{C}$.

\subsection{Calculation model}

The 3D model used when performing numerical calculations of the resistance projection cross-wire welding is presented in Fig. 2. The model-related assumptions involved copper electrodes (A2/2), welded material-aluminium bars grade AA5182 [12] having a diameter of $4 \mathrm{~mm}$ and a length of $2 \times 6 \mathrm{~mm}$ (Fig. 2a). The 3D model was composed of 11.083 mesh nodes and 9.404 elements. To provide necessary computational accuracy, the mesh was concentrated in the bar contact area (Fig. 2b).

The computational model in relation to electrodes was simplified. The water cooling was replaced with air cooling. However, the above-named change did not affect the result of calculations during a single welding cycle, lasing several hundred milliseconds (weld + hold).

The analysis involved both the PFS and the EFS. Criteria adopted when performing calculations were the following:

(1) obtainment of a nominal weld nugget diameter of $1.6 \mathrm{~mm}$,

(2) bar penetration depth - max. $20 \%$ of the thickness of elements subjected to welding $(\Delta \mathrm{l}=1.6 \mathrm{~mm})$,

(3) lack of expulsion,

(4) lack of visible bar deformation (bending),

(5) maximum current flow time of $63 \mathrm{~ms}(3 \mathrm{~ms}$ up-slope, $60 \mathrm{~ms}$ main time),

(6) maximum temperature in the contact area between the electrode and the welded material of $500{ }^{\circ} \mathrm{C}$.
Fig. 2 Geometry of the 3D model of cross-wire welding (Al 5182)

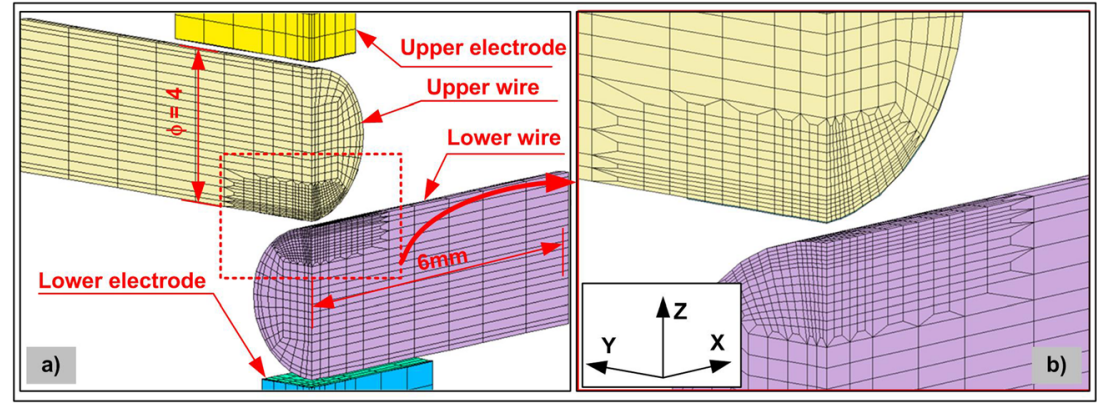



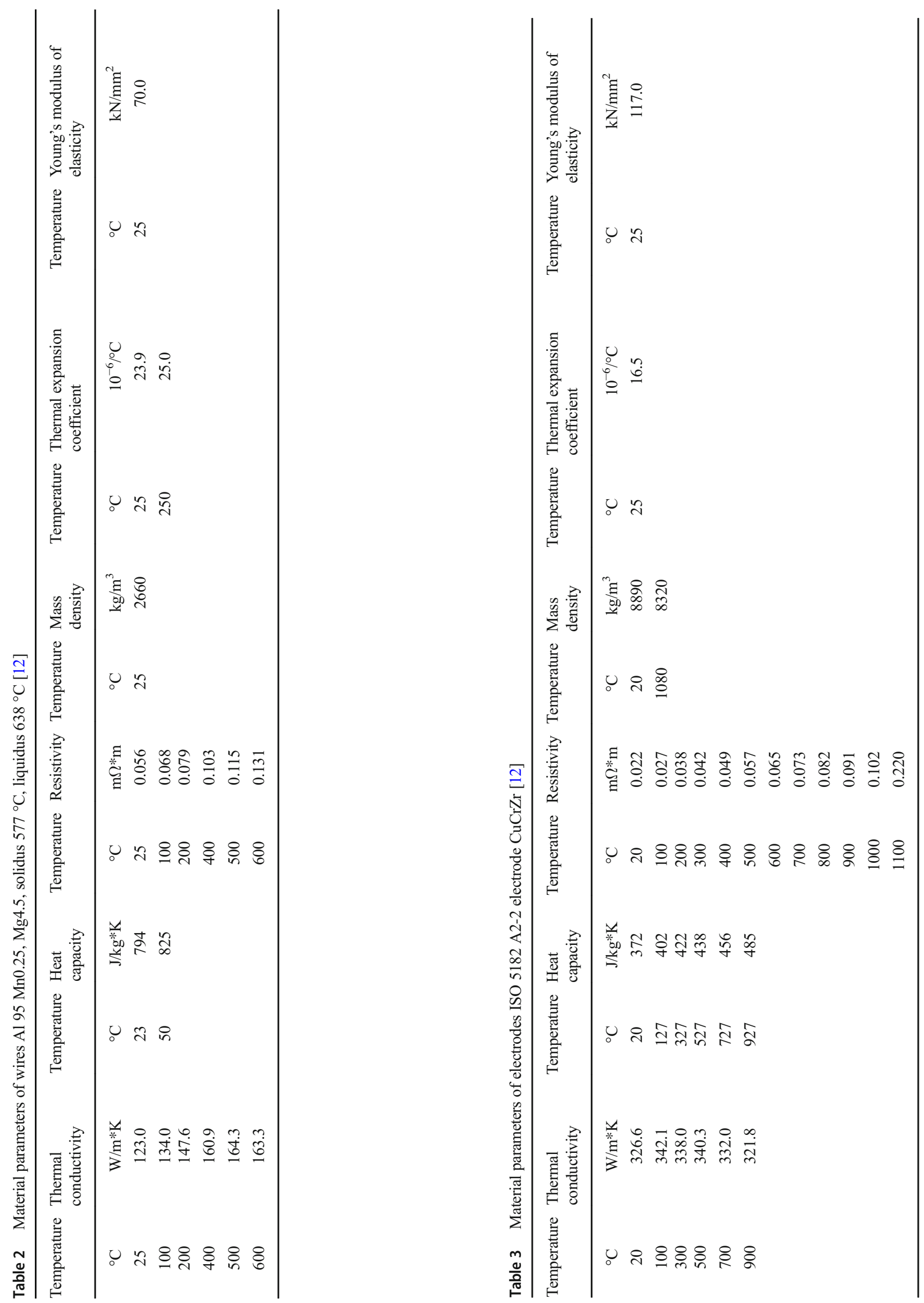
Table 4 Pre-set parameters and characteristic parameters of selected variants in numerical calculations

\begin{tabular}{|c|c|c|c|c|c|c|c|c|c|}
\hline \multirow{2}{*}{ No. } & \multirow{2}{*}{$\begin{array}{l}\text { Variant } \\
1\end{array}$} & \multirow{2}{*}{$\begin{array}{l}\text { Current } \\
{ }^{\mathrm{kA}} \\
2\end{array}$} & \multirow{2}{*}{$\begin{array}{l}\text { Welding } \\
\text { time } \\
\mathrm{ms} \\
3\end{array}$} & \multirow{2}{*}{$\begin{array}{l}\text { Force } \\
\mathrm{kN} \\
4\end{array}$} & $\begin{array}{l}\text { Penetration } \\
\Delta \mathrm{l} \\
\mathrm{mm}\end{array}$ & $\begin{array}{l}\text { Weld } \\
\text { diameter }\end{array}$ & \multirow{2}{*}{$\begin{array}{l}\text { Weld } \\
\text { volume } \\
\mathrm{mm}^{3} \\
7\end{array}$} & \multirow{2}{*}{$\begin{array}{l}\text { Energy } \\
\mathrm{kJ} \\
8\end{array}$} & \multirow{2}{*}{$\begin{array}{l}\text { Remarks } \\
9\end{array}$} \\
\hline & & & & & 5 & 6 & & & \\
\hline \multicolumn{10}{|c|}{ Pneumatic system (PFS) } \\
\hline 1 & $P 1$ & 8.0 & 63 & 1.5 & 1.47 & 0.1 & 0.0 & 0.17 & Overly small weld nugget diameter \\
\hline 2 & $P 2$ & 10.0 & 46 & & 2.38 & 0.1 & 0.0 & 0.17 & Excessive penetration of bars \\
\hline 3 & $P 3$ & 12.0 & 29 & & 1.85 & 0.0 & 0.0 & 0.15 & \\
\hline 4 & P4 & 8.0 & 63 & 1.0 & 1.00 & 0.2 & 0.0 & 0.20 & Overly small weld nugget diameter \\
\hline 5 & $P 5$ & 10.0 & 59 & & 2.13 & 1.5 & 0.9 & 0.23 & $\begin{array}{l}\text { Most favourable welding conditions in spite } \\
\text { of significant penetration of bars }\end{array}$ \\
\hline 6 & P6 & 12.0 & 46 & & 2.54 & 0.2 & 0.0 & 0.30 & Overly small weld nugget diameter \\
\hline 7 & $P 7$ & 8.0 & 63 & 0.5 & 0.57 & 0.3 & 0.1 & 0.25 & Overly small weld nugget diameter \\
\hline 8 & $P 8$ & 10.0 & 8 & & 0.19 & 1.5 & 0.7 & 0.07 & $\begin{array}{l}\text { Unfavourably short welding time, high dynamics of the } \\
\text { force system required }\end{array}$ \\
\hline 9 & $P 9$ & 12.0 & 5 & & 0.15 & 0.8 & 0.1 & 0.05 & Overly small weld nugget diameter \\
\hline \multicolumn{10}{|c|}{ Electromechanical (servo) system (EFS) } \\
\hline 10 & E1 & 8.0 & 38 & servo & 0.6 & 1.95 & 4.5 & 0.16 & OK, full weld nugget, nugget diameter $>1.6 \mathrm{~mm}$, \\
\hline 11 & $\mathbf{E 2}$ & 9.0 & 25 & force & 1.2 & 2.00 & 5.3 & 0.10 & penetration of bars $<1.6 \mathrm{~mm}$ \\
\hline 12 & $\mathbf{E 3}$ & 10.0 & 20 & & 1.5 & 2.20 & 5.6 & 0.13 & \\
\hline
\end{tabular}

Italicized entries indicate unacceptable param., bold entries indicate acceptable param., italic bold entries indicate the most-beneficial welding conditions

The FEM calculations involved the adoption of material data form the software programme database (SORPAS) [12]:

(i) Aluminium bars grade Al 5182-designation of SORPAS AA5182(O) material database: Al 95 Mn0.25 $\mathrm{Mg} 4.5$, solidus $577^{\circ} \mathrm{C}$, liquidus $638^{\circ} \mathrm{C}$ (Table 2).

(ii) Electrodes grade $\mathrm{A} 2 / 2 \mathrm{CuCrZr}$ (Table 3).

\subsection{Process parameters}

On the basis of related standards and instructions, the following welding parameters were assumed: (i) current intensity I = $8 / 9 / 10 / 11 / 12 \mathrm{kA}$, up-slope $3 \mathrm{~ms}+$ main welding time (maximum) $60 \mathrm{~ms}$ [13-16], (ii) force $F=1.5 / 1.25 / 1.0 / 0.75 /$ $0.5 \mathrm{kN}$ in relation to the PFS and (iii) displacement control in relation to the EFS. The remaining welding technology parameters included an initial squeeze time of $100 \mathrm{~ms}$, a final hold time of $500 \mathrm{~ms}$ and the use of a DC inverter welding machine $(1 \mathrm{kHz})$.

Table 4 presents pre-set parameters and characteristic parameters of selected variants used in the numerical calculations. The variants related to the PFS are designated as P1$\mathrm{P} 9$, whereas those related to the EFS are designated as E1-E3.

The analysis of the welding process involving the use of the PFS aimed to test and present the course of the variability of resultant process parameters and to identify the most favourable welding conditions. The results obtained in the analysis revealed the lack of welding process monotonicity in relation to a force of $0.75 \mathrm{kN}$. For this reason, it was necessary to perform additional calculations in relation to a force of $0.7 \mathrm{kN}$ and that of $0.8 \mathrm{kN}$. In total, the welding process was analysed at 35 points $(I=8,9,10,11,12 \mathrm{kA}$ and $F=1.5,1.25$, $1.0,0.8,0.75,0.7$ and $0.5 \mathrm{kN})$.

The numerical optimisation of the process was performed in relation to the EFS and lower values of welding current analysed in relation to the PFS (8/9/10 kA). The numerical calculations were performed until one of the (six) previously adopted boundary criteria was obtained.

The analysis of the PFS-related results in Table 4 revealed that it was not possible to obtain a proper weld nugget within the analysed range of current $(8.0-12.0 \mathrm{kA})$ and electrode force $(1.5-0.5 \mathrm{kN})$.

\section{FEM calculation results}

\subsection{Calculation results related to the pneumatic system}

The results of numerical calculations in relation to the PFS are presented in Fig. 3 and in Table 5. The numerical calculation results are presented in spatial charts developed using the Statistica software programme [17]. Figure 3 (in the form of a surface chart) presents the formation of a weld nugget (Fig. 
Fig. 3 Course of the variability of characteristic parameters in relation to the PFS ( $\mathrm{Al}$ 5182, $\phi=$ $4.0 \mathrm{~mm}$ ). a Weld nugget diameter. b Current flow time. c Electrode displacement (penetration of bars). d Energy supplied to the weld

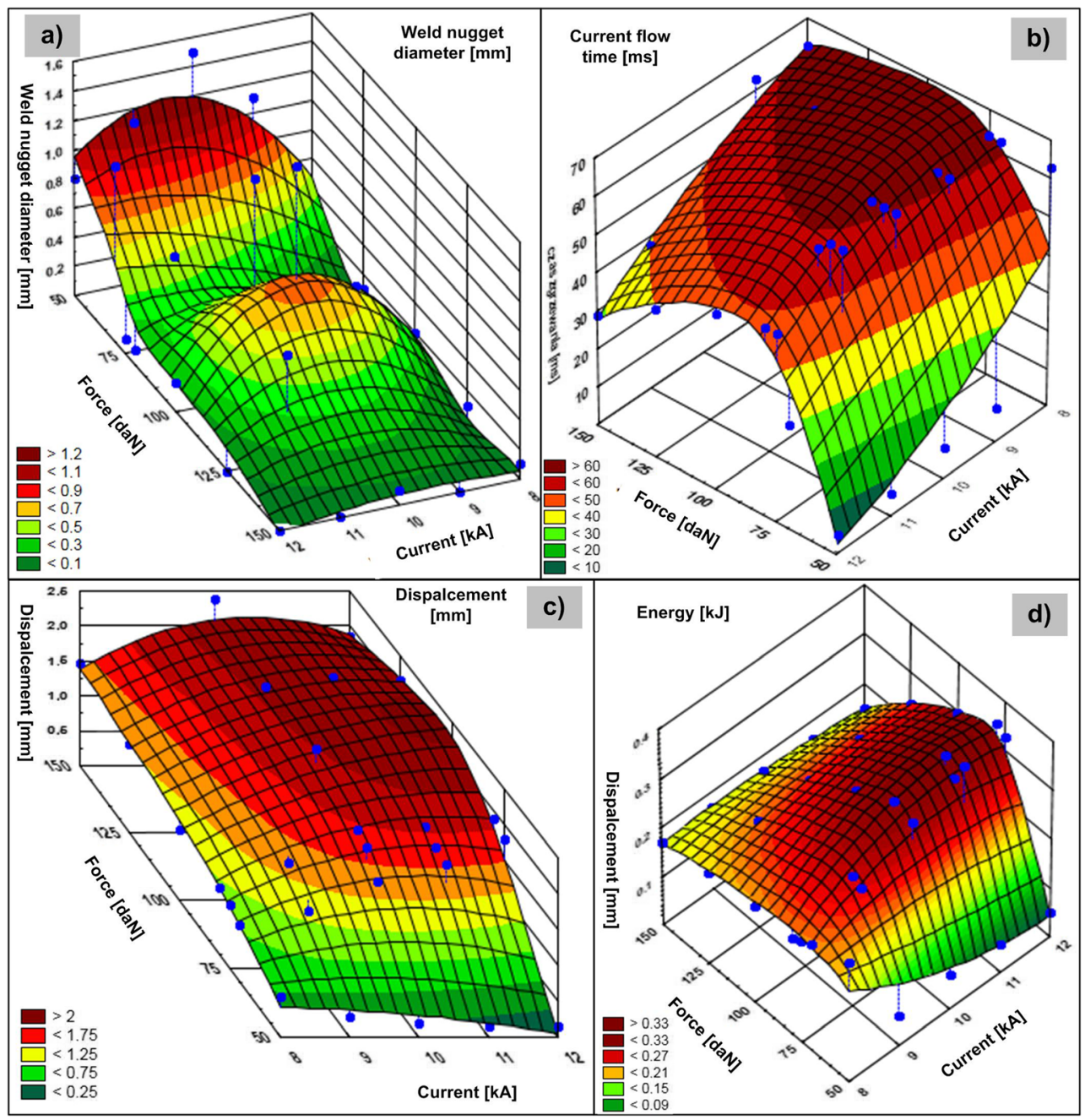

3a), welding time (Fig. 3b), bar penetration depth (electrode displacement) (Fig. 3c) and energy supplied during welding (Fig. 3d). Dependences are presented for various values of welding current and electrode force.

Numerical values connected with the graphic presentation of the results shown in Fig. 3a-d are presented in Table 5(a-d). Table 5(e-g) contains the following additional information concerning:

- obtained criterion (Table 5(e)), i.e.:

- $t$-maximum heating time (current flow time, $63 \mathrm{~ms}$ ),

- $\quad D$-maximum electrode displacement (1.6 mm, $20 \%$ of the bar thickness),

- E-expulsion,

- weld (Table 5(f)), i.e.:

- $\quad L$-weld nugget diameter below $0.7 \mathrm{~mm}$,

- $\quad R$-ring-shaped weld nugget $(0.7 \mathrm{~mm}<D$ (weld nugget diameter) $<=1.5 \mathrm{~mm}$,

- $F$-full weld nugget $(1.90 \mathrm{~mm}<D$ (weld nugget diameter)),

- weld nugget volume (Table 2).
The results presented in Table 5 provide more information concerning the course of the variability of characteristic parameters presented in Fig. 3. The conclusions based on the analysis of the results presented in Fig. 3 and Table 5 are the following:

- maximum obtainable weld nugget diameter amounted to $1.5 \mathrm{~mm}$ (Table 5(a)-parameter field 1),

- within the entire range of the variability of welding current and electrode force parameters, including the largest obtained weld nugget diameter, i.e. from 1.0 to $1.5 \mathrm{~mm}$, the obtained weld was ring-shaped (ring weld) (Table 5(f)-parameter field 2),

- criterion of the exceeding of the maximum time of welding current flow $(63 \mathrm{~ms})$ was observed in relation to lower welding current values (Table 5(b) - parameter field 3a; Table 5(e) - parameter field 3b),

- greatest volumes of molten (welded) metal were observed for the highest values of welding current and the lowest values of electrode force (Table 5(g) - parameter field 4). In relation to such welding parameters, the value of welding energy was relatively low 
Table 5 FEM calculation results in relation to cross-wire welding (AL 5182)

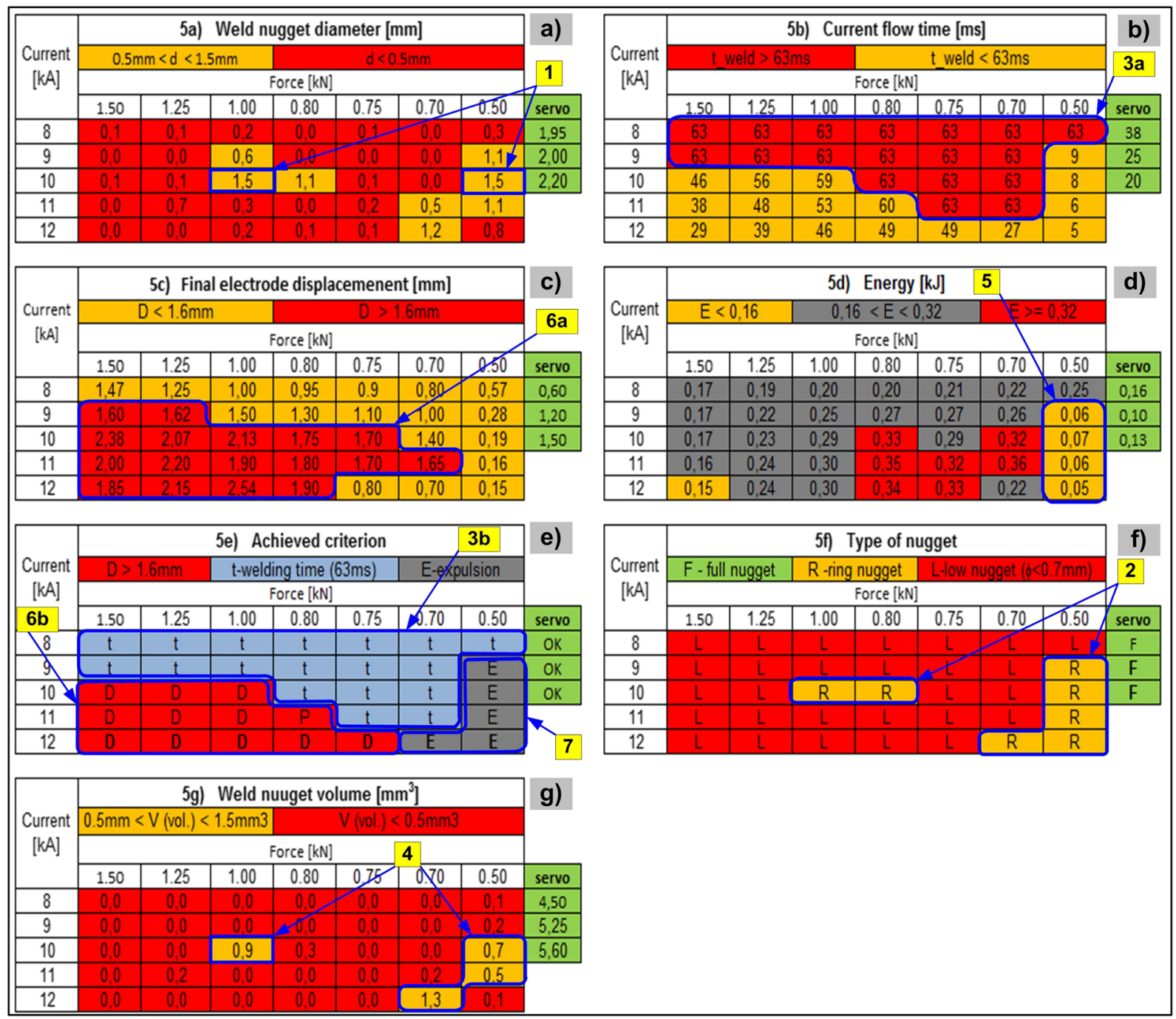

(Table 5(d)-parameter field 5). The welding time was very short and amounted to several milliseconds. The slight exceeding of the welding time creates the risk of expulsion (Fig. 5(e)-parameter field 7). The welding time was determined as a result of the exceeding of the criterion of the maximum temperature in the contact between the electrode and the material being welded,

- above-standard penetration of bars, i.e. above the permissible value, was obtained in lower values of welding current and higher values of electrode force (Table 5(c) parameter field $6 \mathrm{a}$, final penetration) and Table 5(e) - parameter field $6 \mathrm{~b}$ (penetration amounting to $\Delta \mathrm{l}=1.6 \mathrm{~mm}$, obtained during the flow of current),

- risk of expulsion was observed for the lowest value of electrode force and higher values of welding current (Table 5(e)-parameter field 7).
However, the most important problem was a failure to satisfy the primary criterion, i.e. the nominal weld nugget diameter, set at $1.6 \mathrm{~mm}$ and the obtainment of the full weld nugget.

In addition, Table 5 presents the results of the numerical calculations obtained in relation to the EFS (green colour). All of the assumed criteria-related conditions were satisfied.

\subsection{Comparison of PFS and EFS system}

The comparison of the FEM calculation results and temperature distribution for both, i.e. PFS and EFS, are presented in Fig. 4. The presented test results are related to two selected welding current values, i.e. $8 \mathrm{kA}$ and $10 \mathrm{kA}$.

For the PFS and a welding current of $8 \mathrm{kA}$, the distribution of temperature is presented within the entire range of temperature subjected to analysis, i.e. from ambient temperature to the melting point (liquidus) (Fig. 4(a)). In 
Fig. 4 Temperature distribution in the welding area in relation to $\mathbf{a} / \mathbf{b} / \mathbf{c}$ PFS (I $=8.0 \mathrm{kA}$ and $10.0 \mathrm{kA}, F=1.0 \mathrm{kN})$ and $\mathbf{d}$ EFS $(I=8.0 \mathrm{kA}$, servo force)

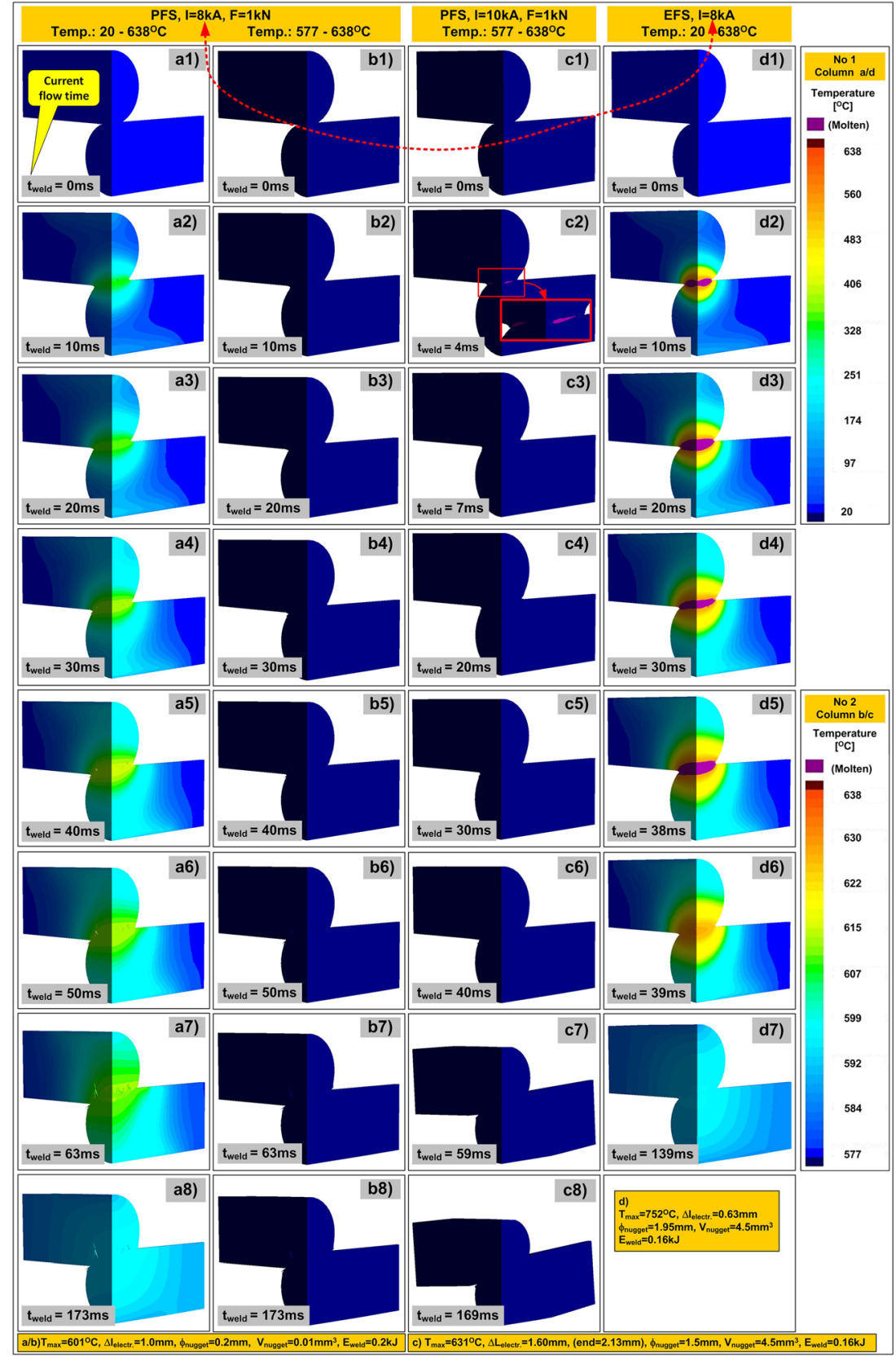

the above-named temperature range, the melting of the metal was not observed and the weld nugget diameter calculated by the SOPRPAS software programme only amounted to $0.2 \mathrm{~mm}$. Figure 4(b) presents the distribution of temperature within the range of solidus $\left(577^{\circ} \mathrm{C}\right)$ to liquidus $\left(638{ }^{\circ} \mathrm{C}\right)$ temperature. In the above-presented case, the melting of the material did not take place, which could suggest that the joint was formed in the solid state in the entire contact (welding) area.

As regards the higher current value, i.e. $10 \mathrm{kA}$, and the PFS, as a result of the welding area plasticisation and the effect of constant electrode force, melted metal was pushed outside. As a result, the contact area between welded materials (bars) became too large, which, consequently, led to a significant decrease in current density and the immediate cooling of the weld material. The melting of the material was visible for only one millisecond (Fig. 4(c2)).

The temperature distribution results in relation to the EFS and a welding current value of $8 \mathrm{kA}$ are presented in Fig. 4(d). The completely different method of electrode force control led to the clearly visible melting of the material being welded and the formation of a full weld nugget (Fig. 4(d)). In the above case, the presentation of temperature distribution within the entire range of temperature being analysed, i.e. from ambient temperature to the melting point (liquidus) - Fig. 4(d) - was very clear. In the analysed case of the welding of aluminium 
Fig. 5 FEM calculation results. a Electrode force. $\mathbf{b}$ Instantaneous power. c Electrode displacement (bar penetration depth). d Weld nugget diameter: curves 1 and 2 PFS $(I=8.0 \mathrm{kA}, F=1.0 \mathrm{kN})$; curves 3 and 4 EFS $(I=8.0 \mathrm{kA}$, servo force)

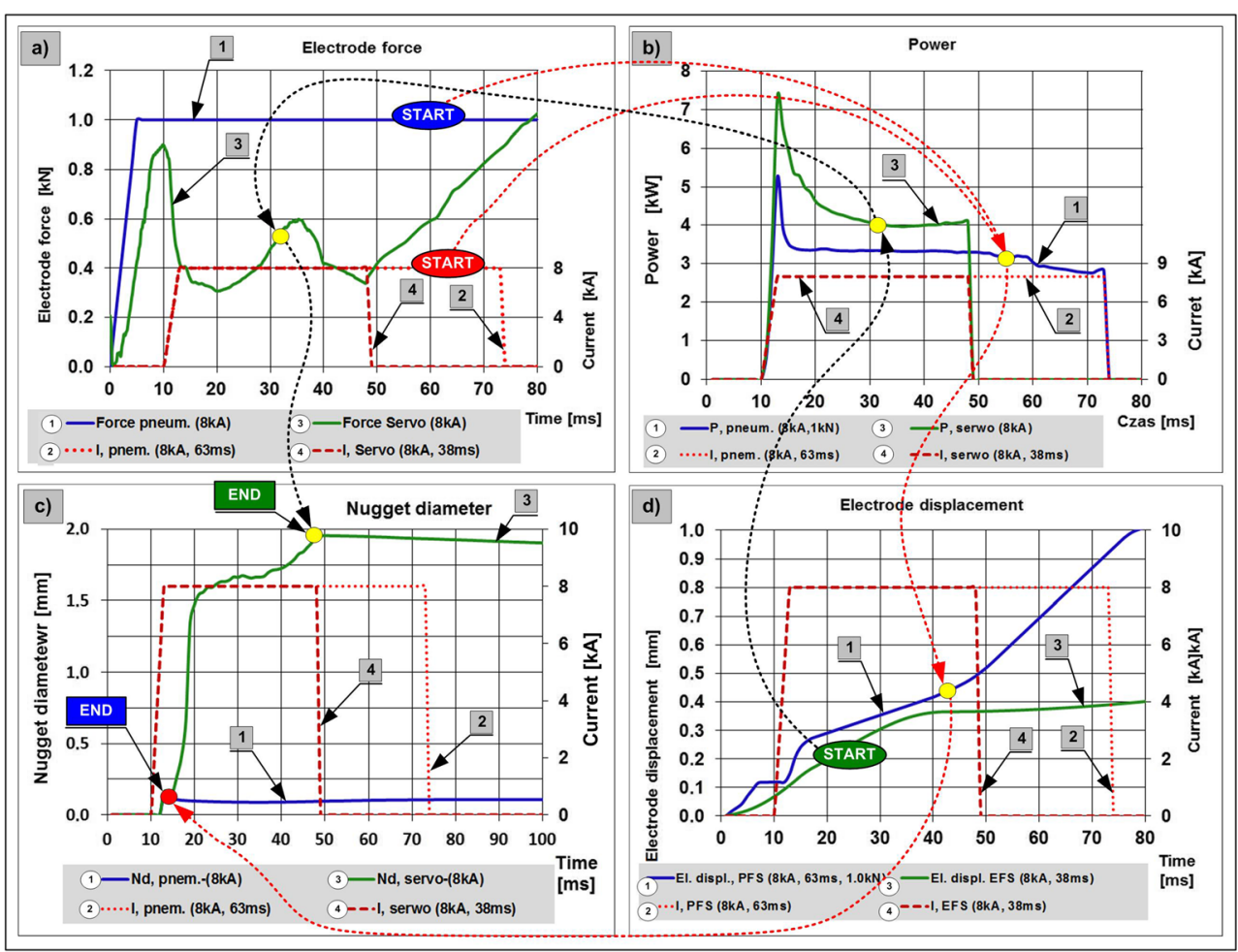

bars (Al 5182), the disconnection of power supply (current) resulted in the immediate (within $1 \mathrm{~ms}$ ) reduction of temperature below the melting point (Fig. 4(d5-6)). It should be mentioned that for a welding current value of $8 \mathrm{kA}$ and the PFS, the joint was obtained in the solid state in the entire welding area.

\section{Process optimisation}

The welding process optimisation was performed by comparing the courses/waveforms of characteristic parameters (electrode displacement, instantaneous power, weld nugget diameter and electrode force) in relation to two electrode force systems (PFS and EFS) (Fig. 5). The comparison was performed involving the same value of welding current, i.e. $8 \mathrm{kA}$. When the PFS was used, the above-named value of welding current did not enable the obtainment of a proper weld. The melting of the material subjected to welding was little (or nearly not) visible (Fig. 4(b)). In turn, the use of the EFS enabled the obtainment of a weld nugget having the previously assumed diameter, i.e. exceeding $1.6 \mathrm{~mm}$ (Fig. 4(c)).

Curves numbered 1 and 2 in Fig. 5 are related to the PFS, whereas curves number 3 and 4 are related to the EFS, where curves 2 and 4 present the waveforms of welding current (in relation to the PFS and EFS respectively).

The course of the process performed using the PFS can be described as presented below. The pre-set constant electrode force (Fig. 5a, curve 1) as well as the specific value of welding current and the time of its flow (Fig. 5a, curve 2) generates specific welding power (Fig. 5b, curve 1) and the related displacement of electrodes (Fig. 5d, curve 1). The above-named factors lead to the obtainment of a weld nugget having a specific shape and dimensions (Table 2, Fig. 5c, curve 1), e.g. diameter of only $0.2 \mathrm{~mm}$.

A welding current of $8 \mathrm{kA}$ is too low and is only responsible for the plasticisation of the material and the formation of the excessive contact area between elements subjected to welding. Current density is too low and the melting of the material to be welded is not possible. The material in the contact area is only heated and plasticised. The maximum
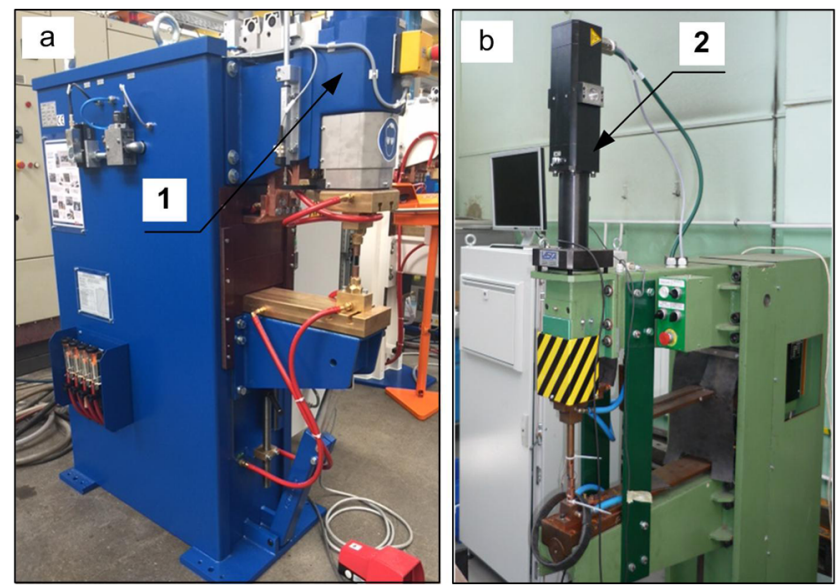

Fig. 6 Test station for technological welding tests performed using a PFS and $\mathbf{b}$ EFS. (1) Pneumatic actuator. (2) Servomotor 


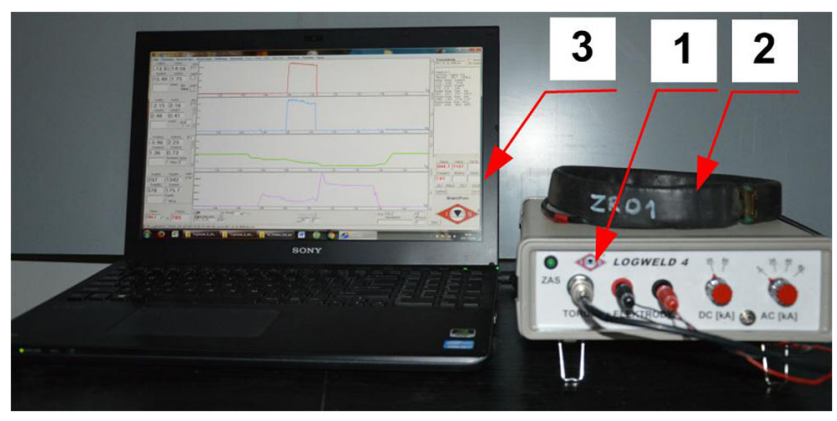

Fig. 7 LogWeld 4 measurement device for measurements of characteristic parameters of the resistance welding process (welding current and voltage, electrode force and displacement). (1) Measurement interface. (2) Toroid. 3 PC

welding time amounting to $63 \mathrm{~ms}$ is exceeded and the related criterion is not satisfied.

The initial stage of the cross-wire welding optimisation involved an appropriate change in the course of electrode displacement (bar penetration depth; Fig. 5d) (curve no. 3) resulting from the use of the EFS and from the application of an appropriate electrode displacement control algorithm. The essence of the change in the course of electrode displacement involved the direct control of this parameter, particularly during the flow of welding current. In general, it is necessary to slow down the process of electrode displacement in order to obtain more favourable power density distribution and to generate higher welding power (Fig. 5b, curve 3 ) in comparison with those obtained during welding performed using the PFS. Slower electrode displacement accompanied by constant welding current increases resistance in the contact area, leading to an increase in welding power. As a result, the sequence of events is the following: (i) contact area between elements being welded is smaller, (ii) resistance in the contact is higher and (iii) temperature distribution in the welding area is more favourable. All of the above-named factors enable the obtainment of a weld nugget having a diameter exceeding $1.6 \mathrm{~mm}$ (Fig. 5c, curve 3).

The final effect of the above-presented manner of control is the appropriate course of electrode force (Fig. 5a, curve 3). Electrode force affects the value of resistance, particularly in the contact areas (especially in the welded bar-welded bar configuration), which, in turn, is responsible for the appropriate space distribution of power and welding energy. Consequently, the foregoing translates into the appropriate distribution of temperature in the welding area, leading to the melting of a material subjected to welding and enabling the formation of a weld of appropriately greater diameter.

When summarising this part of analysis related to the value of welding current amounting to $8.0 \mathrm{kA}$ (and recognised as overly low to obtain a proper joint using the PFS), it is necessary to state that the use of the EFS and appropriate electrode force and/or displacement control significantly improve the quality of a welding process and enable the obtainment of a full weld nugget having the previously assumed diameter (> $1.6 \mathrm{~mm}$ ) obviously after satisfying the remaining requirements (quality criteria).

The results presented in Fig. 5 were obtained on the basis of calculations performed using the SORPAS 3D model.

\section{Experimental verification}

Experimental tests were performed using test rigs equipped with DC inverter welding machines (DC $1 \mathrm{kHz}$; Fig. 6). The electric parameters of the welding process were recorded using the LogWeld 4 device (Fig. 7).

The numerical calculation results were verified experimentally. The experimental tests were performed for the nine variants presented in Table 4 and concerning the PFS. Destructive (peeling) tests confirmed the formation of a ring weld in each of the variants (P1 through P9). None of the variants related to the PFS satisfied the previously assumed criteria. Variant P5 was considered as the closest to the most favourable welding conditions. Further technological welding tests (Table 6: variants PE1 and PE2) were performed for parameters similar to variant P5 (Table 4). The results concerning the pre-set parameters and the parameter characteristic of technological welding tests in relation to the PFS (variants PE1 and PE2) are presented in Table 6, whereas the results in the form of a joint

Table 6 Pre-set parameters and parameter characteristic of the PFS

\begin{tabular}{|c|c|c|c|c|c|c|c|c|c|c|c|}
\hline \multirow[t]{4}{*}{ No. } & \multirow[t]{4}{*}{ Variant no. } & \multicolumn{6}{|c|}{ Present parameters } & \multicolumn{4}{|c|}{ Recorded parameters } \\
\hline & & \multirow{3}{*}{$\begin{array}{l}\text { Electrode force } \\
\mathrm{kN} \\
\mathrm{A}\end{array}$} & \multicolumn{2}{|c|}{ Up-slope } & \multicolumn{2}{|c|}{$\begin{array}{l}\text { Main welding } \\
\text { time }\end{array}$} & \multirow{3}{*}{$\begin{array}{l}\text { Total current (I rms) } \\
\mathrm{kA} \\
\mathrm{D}\end{array}$} & \multirow{3}{*}{$\begin{array}{l}\text { Energy } \\
\\
\mathrm{kJ} \\
\mathrm{E}\end{array}$} & \multirow{3}{*}{$\begin{array}{l}\text { Bar penetration } \\
\mathrm{mm} \\
\mathrm{F}\end{array}$} & \multirow{3}{*}{$\begin{array}{l}\text { Weld diameter } \\
\\
\mathrm{mm} \\
\mathrm{G}\end{array}$} & \multirow{3}{*}{$\begin{array}{l}\text { Number of tests } \\
\text { pcs } \\
\mathrm{H}\end{array}$} \\
\hline & & & $\begin{array}{l}\text {-Current } \\
\text { kA }\end{array}$ & $\begin{array}{l}\text { Time } \\
\mathrm{ms}\end{array}$ & $\begin{array}{l}\text { Current } \\
\mathrm{kA} \\
\mathrm{C} 1\end{array}$ & $\begin{array}{l}\text { Time } \\
\mathrm{ms}\end{array}$ & & & & & \\
\hline & & & B1 & B2 & $\mathrm{C} 1$ & $\mathrm{C} 2$ & & & & & \\
\hline 1 & PE1 & 1.0 & 10.0 & 3 & 10.0 & $40-60$ & 10.0 & 0.23 & 1.50 & 1.5 & 20 \\
\hline 2 & PE2 & 1.0 & 9.5 & 3 & 9.5 & $50-70$ & 9.5 & 0.21 & 1.38 & 1.3 & 20 \\
\hline
\end{tabular}

$I_{r m s}$ root-mean-square current, $P E$ pneumatic experiment 
Fig. 8 Metallographic test results. a PFS. b EFS

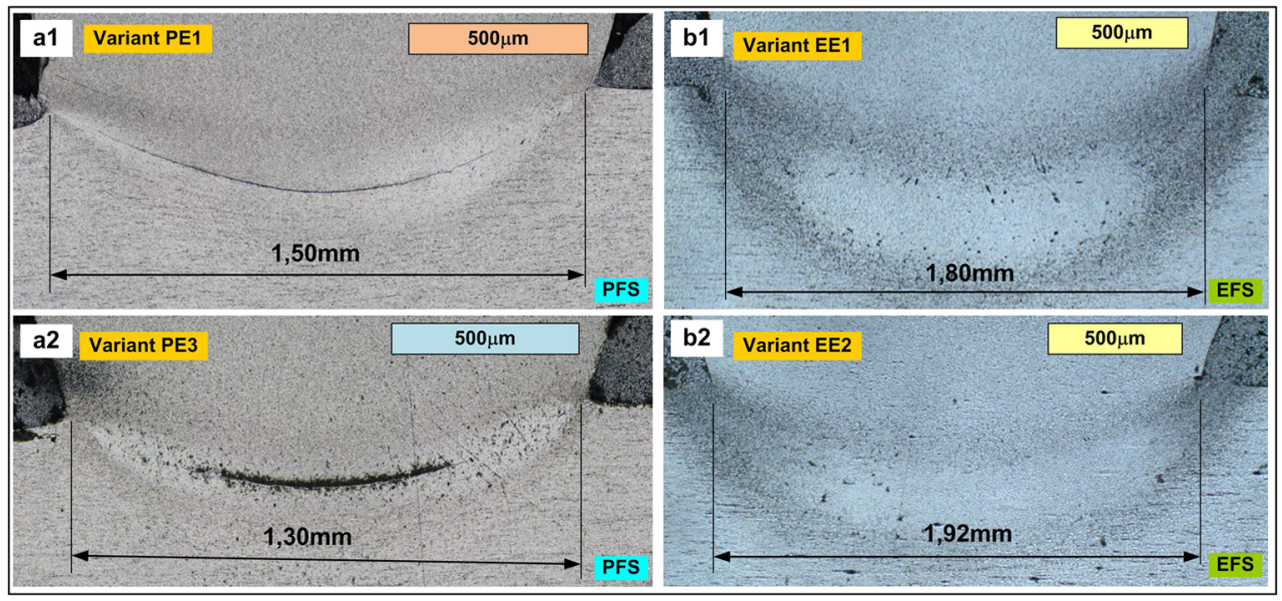

structure are presented in Fig. 8a. The electric parameters of the welding process, i.e. welding current and voltage, were recorded using the LogWeld 4 measurement device.

The technological parameters related to variants PE1 and PE2 were the following: (i) force $F=1.0 \mathrm{kN}$, (ii) welding current $I=9.5-10 \mathrm{kA}$ and (iii) welding time $t=40-70 \mathrm{~ms}$. For the above-presented welding technology parameters, the FEM calculation results indicated the obtainment of a weld nugget having the greatest diameter $(1.5 \mathrm{~mm})$, yet still being ring-shaped. Metallographic tests confirmed the results obtained in the numerical calculations, i.e. the formation of a ring weld.

Afterwards, the welding process was subjected to optimisation by using lower welding current values restricted within the range of 8.0 to $8.5 \mathrm{kA}$ and an appropriate force profile involving the use of the EFS (Table 7: variants EE1 and EE2). The results concerning the pre-set parameters and the parameter characteristic of technological welding tests in relation to the EFS are presented in Table 7, whereas the results in the form of a joint structure are presented in Fig. 8 b. The electric parameters of the process, i.e. welding current and voltage, were recorded using the LogWeld 4 measurement device.

Figure $8 \mathrm{~b}$ presents the melting of the welded materials in the entire weld area. Importantly, the melting of the material also took place in the central part of the joint.

\section{Conclusions}

The adjustment of the most favourable parameters of the cross-wire projection welding technology involving the use of the PFS, particularly in relation to soft materials, e.g. aluminium alloys, proves very difficult (nearly impossible). In the case of the aforesaid force system, the electrode force is excessively high for short welding times and high welding current. The above-named conditions are conflicting and constitute significant limitations to the adjustment of welding parameters. The primary limitation is the dynamics of the electrode force system, i.e. the lacking possibility of fast electrode force control within a short time of current flow.

Table 7 Pre-set parameters and parameter characteristic of the EFS

\begin{tabular}{|c|c|c|c|c|c|c|c|c|c|c|c|c|c|c|c|c|c|}
\hline \multirow[t]{6}{*}{ No. } & \multirow{6}{*}{$\begin{array}{l}\text { Variant } \\
\text { no. }\end{array}$} & \multicolumn{12}{|c|}{ Present parameters } & \multicolumn{4}{|c|}{ Recorded parameters } \\
\hline & & \multicolumn{3}{|l|}{ Force } & \multirow{2}{*}{\multicolumn{2}{|c|}{ Up-slope }} & \multirow{2}{*}{\multicolumn{2}{|c|}{$\begin{array}{l}\text { Main } \\
\text { welding } \\
\text { time }\end{array}$}} & \multirow{3}{*}{$\begin{array}{l}\text { Total } \\
\text { current }\end{array}$} & \multirow{2}{*}{\multicolumn{4}{|c|}{$\begin{array}{l}\text { Electrode displacement } \\
\text { and time }\end{array}$}} & \multirow[t]{3}{*}{ Energy } & \multirow{3}{*}{$\begin{array}{l}\text { Bar } \\
\text { penetration }\end{array}$} & \multirow{3}{*}{$\begin{array}{l}\text { Weld } \\
\text { diameter }\end{array}$} & \multirow{3}{*}{$\begin{array}{l}\text { Number of } \\
\text { tests }\end{array}$} \\
\hline & & Initial & Min. & Max. & & & & & & & & & & & & & \\
\hline & & & & & Cur. & Time & Cur. & Time & & \multirow{2}{*}{\multicolumn{2}{|c|}{$\begin{array}{ll}\mathrm{t}_{1} / & \mathrm{t}_{2} / \\
-\Delta \mathrm{l}_{1} \quad \Delta \mathrm{l}_{2} \\
\mathrm{~ms} / \mathrm{mm}\end{array}$}} & \multirow{2}{*}{$\begin{array}{l}\mathrm{t}_{3} / \\
\Delta \mathrm{l}_{3}\end{array}$} & \multirow{2}{*}{$\begin{array}{l}\mathrm{t}_{4} / \\
\Delta \mathrm{l}_{4}\end{array}$} & & & & \\
\hline & & \multicolumn{3}{|l|}{$\mathrm{kN}$} & $\mathrm{kA}$ & $\mathrm{ms}$ & $\mathrm{kA}$ & $\mathrm{ms}$ & $\mathrm{kA}$ & & & & & \multirow{2}{*}{$\begin{array}{l}\mathrm{kJ} \\
\mathrm{F}\end{array}$} & \multirow{2}{*}{$\begin{array}{l}\mathrm{mm} \\
\mathrm{G}\end{array}$} & \multirow{2}{*}{$\begin{array}{l}\mathrm{mm} \\
\mathrm{H}\end{array}$} & \multirow{2}{*}{$\begin{array}{l}\text { pcs } \\
\text { I }\end{array}$} \\
\hline & & A1 & $\mathrm{A} 2$ & A3 & B1 & B2 & $\mathrm{C} 1$ & $\mathrm{C} 2$ & $\mathrm{D}$ & E0 & E1 & E2 & E3 & & & & \\
\hline 1 & EE1 & 1.0 & 0.4 & 1.0 & 8.0 & 3 & 8.0 & 45 & 8.0 & $\begin{array}{c}10 \\
0.08\end{array}$ & $\begin{array}{c}30 \\
0.25\end{array}$ & $\begin{array}{c}10 \\
0.05\end{array}$ & $\begin{array}{c}30 \\
0.25\end{array}$ & 0.16 & 0.70 & 1.87 & 20 \\
\hline 2 & EE2 & 1.0 & 0.4 & 1.0 & 8.5 & 3 & 8.5 & 40 & 8.5 & $\begin{array}{c}10 \\
0.08\end{array}$ & $\begin{array}{c}25 \\
0.25\end{array}$ & $\begin{array}{c}7 \\
0.05\end{array}$ & $\begin{array}{c}30 \\
0.25\end{array}$ & 0.20 & 0.75 & 1.92 & 20 \\
\hline
\end{tabular}

$I_{r m s}$ root-mean-square current, $E E$ electromechanical experiment 
When using the PFS for the cross-wire welding of aluminium bars, it is difficult (nearly impossible) to obtain a full weld nugget. The application of all of the analysed parameters ended up in the obtainment of the unfavourable ring weld.

The improvement of the welding process (extension of the parameter window) requires the use of the EFS. During operation involving the displacement of electrodes, it is possible to adjust more favourable electrode displacement trajectory enabling the obtainment of more favourable current density distribution, more favourable space distribution of welding power, generation of higher energy in the central zone of a joint, generation of significantly higher temperature in the aforesaid area and, finally, the obtainment of a larger full weld nugget.

The use of the EFS makes it possible to control the displacement of electrodes during the flow of current as well as to obtain the assumed final displacement of electrodes resulting in the obtainment of specific (smaller) projection height reduction.

A characteristic of the PFS is the fact that (electrode) force is a pre-set parameter, whereas the resultant parameter is the displacement of electrodes, not controlled in any manner.

The new method of electrode force exertion involves the pre-setting of displacement, particularly during the flow of welding current. This means, that displacement is the pre-set parameter and force is the result. The research results extend knowledge about welding technologies concerning a different manner of electrode force and/or displacement control. The test results demonstrated that it is possible to apply the innovative control of electrode displacement. The foregoing may revolutionise and change previous views concerning the course of the resistance welding process and significantly influence the development of the technology.

Funding information This work was co-financed by the Polish National Centre for Research and Development (NCBR) under project no. TANGO1/267374/NCBR/2015.

Open Access This article is distributed under the terms of the Creative Commons Attribution 4.0 International License (http:// creativecommons.org/licenses/by/4.0/), which permits unrestricted use, distribution, and reproduction in any medium, provided you give appropriate credit to the original author(s) and the source, provide a link to the Creative Commons license, and indicate if changes were made.

Publisher's note Springer Nature remains neutral with regard to jurisdictional claims in published maps and institutional affiliations.

\section{References}

1. Zhang H, Senkara J (2011) Resitance welding fundamentals and applications. Taylor\&Francis Group

2. Zhang X, Chen G, Zhang Y, Lai H (2009) Improvement of resistance spot weldability for dual-phase (DP600) steels using servo gun. J Mater Process Technol 209:2671-2675

3. Slavick SA (1999) Using servo guns for automated resistance welding. Weld J 78(7):29-32

4. Tang H, Hou W, Hu S (2002) Forging force in resistance spot welding. Proc Inst Mech Eng B J Eng Manuf 216(7):957-968. https://doi.org/10.1243/09544050260174166

5. Gould JE (2012) Joining aluminum sheet in the automotive industry - a 30 year history. Welding Journal (Welidng Research) vol. 91. January, pp. 23-34

6. Zhang XQ, Chen GL, Zhang YS (2008) On-line evaluation of electrode wear by servo gun. Int J Adv Manuf Technol 36:681-688

7. Mikno Z (2016) Projection welding with pneumatic and servomechanical electrode operating force systems. Welding Journal (Welding Research) 2016 vol. 95. August, pp. 286-299

8. Mikno Z, Stepien M, Grzesik B (2017) Optimization of resistance welding by using an electric servo actuator. Welding in the World, Open Access 21 February 2017. 61, 453, 462 https://doi.org/10. 1007/s40194-017-0437-x

9. Mikno Z, Bartnik Z, Ambroziak A and Pietras A (2012) Method for projection resistance welding of steel plates with embossed projections. Patent P. 401723 Polish Patent Office

10. Mikno Z (2018) Projection welding of nuts involving the use of electromechanical and pneumatic electrode force. Int $\mathrm{J}$ Adv Manuf Technol pp. 1-21 https://doi.org/10.1007/s00170-0182525-5

11. Mikno Z, Grzesik G, Stepien (2015) A manner of resistance projection welding in configuration of the cross, mainly for aluminum wires. Patent P.412615 Polish Patent Office

12. The database of the material and electrode parameters: model 3D Version 4.0x64 of the Swantec Inc. SORPAS Software (http:// swantec.com/)

13. Zhang W (2003) Design and implementation of software for resistance welding process simulation. SAE International Journal of Materials and Manufacturing 112(5):556-564. https://doi.org/10. 4271/2003-01-0978

14. Papkala H (2003) Resistance welding of metals. Publishing House KaBe Krosno

15. AWS Welding Handbook $9^{\text {th }}$ edition, vol. 3, welding processes, part 2 chapter 2 , projection welding

16. Projection Welding, Gould, J E (1993) ASM International, ASM Handbook. Vol. 6: welding, brazing, and soldering (USA), 1993: 230-237,

17. Statistica 12, www.statsoft.pl. 